\title{
Sea Level at the Coast from Video-Sensed Waves: Comparison to Tidal Gauges and Satellite Altimetry
}

\author{
G. Abessolo OndoA, ${ }^{\mathrm{a}, \mathrm{b}}$ R. Almar, ${ }^{\mathrm{a}}$ B. CAstelle, ${ }^{\mathrm{c}}$ L. Testut, ${ }^{\mathrm{a}, \mathrm{d}}$ F. LÉGer, ${ }^{\mathrm{a}}$ Z. Sohou, \\ F. BONOU, ${ }^{\mathrm{e}, \mathrm{f}}$ E. W. J. BERGSMA, ${ }^{\mathrm{a}}$ B. MEYSSIGNAC, ${ }^{\mathrm{a}}$ AND M. LARSON ${ }^{\mathrm{g}}$ \\ ${ }^{a}$ LEGOS, OMP, UMR 5566, CNES, CNRS, IRD, University of Toulouse, Toulouse, France \\ ${ }^{\mathrm{b}}$ Ecosystems and Fishery Resources Laboratory, University of Douala, Douala, Cameroon \\ ${ }^{\mathrm{c}}$ EPOC, OASU, UMR 5805, CNRS, University of Bordeaux, Pessac, France \\ ${ }^{\mathrm{d}}$ LIENSs, Université de La Rochelle, CNRS, La Rochelle, France \\ ${ }^{\text {e } L a b o r a t o i r e ~ d ' H y d r o l o g i e ~ M a r i n e ~ e t ~ C o ̂ t i e ̀ r e, ~ I n s t i t u t ~ d e ~ R e c h e r c h e ~ H a l i e u t i q u e ~ e t ~ O c e ́ a n o l o g i q u e ~ d u ~ B e n i n, ~}$ \\ Cotonou, Benin \\ ${ }^{\mathrm{f}}$ Université Nationale des Sciences, Technologie, Ingénierie et Mathématiques, Abomey, Benin \\ ${ }^{\mathrm{g}}$ Water Resources Engineering, Lund University, Lund, Sweden
}

(Manuscript received 25 November 2018, in final form 24 April 2019)

\begin{abstract}
Nearshore complex and energetic hydrodynamic conditions make observing evolving processes during extreme and short-term events difficult. In particular, total sea levels at the coast are hard to measure with current techniques. Sea level is commonly measured with tidal gauges and spaceborne altimetry, which lack essential details of spatial and wave-related sea level variability along the coast. Hence, novel techniques, adapted to nearshore areas, are required. This paper presents the first-time use of video cameras to derive the total sea level at the coast. This novel approach consists of estimating time-varying total water levels by applying a celerity-based depth inversion method, which is conventionally used to estimate bathymetry from video. The video-derived total sea levels are compared to sea levels derived from an in situ acoustic Doppler current profiler (ADCP), the nearest tide gauge, and altimetry. A tidal harmonic analysis is performed on the video-derived water levels, yielding an accurate determination of the dominant tidal harmonics. However, it remains difficult to separate bathymetric changes due to the waves on beaches when rapid morphological changes occur under energetic conditions. Nonetheless, video-derived water-level anomalies are in good agreement with state-of-the-art altimetry products. Although there is still work to be done, the results show the potential to measure total sea level at the coast using video camera systems.
\end{abstract}

\section{Introduction}

The nearshore coastal zone is the interface between land and the continental shelf (Komar 1998; Elko et al. 2014). Coastal areas are often densely populated and evolve under an increasing threat from sea level rise, long-term erosion, extreme storms, and anthropogenic influences (Vousdoukas et al. 2018; Anderson et al. 2018). Remote sensing and in situ instrumentation enabled improved understanding of nearshore hydro- and morphodynamic processes. However, complex and energetic hydrodynamic conditions reduce the possibility to observe a range of processes, such as total coastal sea level fluctuations.

Corresponding author: Gregoire Abessolo Ondoa, gregsolo55@ yahoo.fr
There is a need for observations of sea level at the coast (Cazenave et al. 2018; Melet et al. 2018). More than in other geosciences, nearshore research historically faces difficulties in investigating the complex and energetic environment. Satellite altimetry, optimized for the open ocean, performs poorly within $25 \mathrm{~km}$ of the coast since landmasses perturb the radar signal (Cipollini et al. 2017). Over the past 10 years, significant progress has been made to improve available altimetry data at the coast through several projects, for example, X-TRACK (Birol et al. 2017), PISTACH (Prototype Innovant de Système de Traitement pour les Applications Côtières et l'Hydrologie) and Prototype for Expertise on Ka-Band Altimeter (AltiKa) for Coastal, Hydrology and Ice (PEACHI; Valladeau et al. 2015), and Adaptive Leading Edge Subwaveform (ALES) retracker (Passaro et al. 2014). 
More is to be expected from the French-U.S. Surface Water and Ocean Topography (SWOT) mission. Despite these efforts, spaceborne altimetry still has a relatively low spatial and temporal resolution compared to coastal spatiotemporal scales. Similarly, most tide gauges are limited to deep water or sheltered harbors and omit part of the natural total sea level variability at open coasts (Melet et al. 2016). New radar gauges are exposed to wave effects nowadays but there remains a challenge to understand wave effects on these sensors. Intensive nearshore field experiments with high spatial and temporal sampling rates are scarce. Bathymetric surveys with echo sounders are time consuming and often contain data gaps between the bathymetry and the topography, especially in the micro- to mesotidal regimes. As a result, bridging the knowledge gap between short-term, small-scale dynamics and long-term evolution is a major challenge. This generally holds for most major recent studies dealing with sea level at the coasts (e.g., Idzanovic et al. 2018; Birol et al. 2017; Segura et al. 2018; Melet et al. 2018).

Such limitations also reflect the existing knowledge gap of total sea level propagation across the shelf to the shore during extreme events in which processes vary rapidly (Elko et al. 2014). The nearshore research community, therefore, needs new, better suited, observational tools to provide accurate water-level measurements at complex and energetic coasts, including all contributions to total sea level. The total sea level at the coast (SL) is the superposition of oceanographic, meteorological, hydrological, and geological forcing and constraints (Slangen et al. 2017). This includes contributions due to global warming of the ocean and the transfer of water mass from land ice, land water storage, ocean circulation, and water density variations at global and regional scales [sea level anomaly (SLA)], local effects of astronomical tide (AT), atmospheric surges [inverse barometer (DA) and atmospheric wind (Wi)], and wave transformations $W$ in the surf zone (Melet et al. 2016; Slangen et al. 2017). Therefore, the total sea level can be described by

$$
\mathrm{SL}=\mathrm{AT}+W+\mathrm{Wi}+\mathrm{SLA}+\mathrm{DA} .
$$

Coastal video monitoring systems provide an excellent response to the challenge of observing the water-level contributions at a larger spatial scale. It now offers access to 15 -min frequency and long-term description of the near shore (Holman and Stanley 2007; Almar et al. 2014; Pianca et al. 2015; Angnuureng et al. 2016; Abessolo Ondoa et al. 2017; Bergsma et al. 2019). During the last few decades, progress has been made on estimating variables from shore-based video imagery, such as shoreline position (Boak and Turner 2005; Almar et al. 2012b; Osorio et al. 2012), intertidal beach morphology (Uunk et al. 2010; Osorio et al. 2012), breaking wave height (Almar et al. 2012a), nearshore currents (Radermacher et al. 2014; Almar et al. 2016), water level in the swash zone (Ibaceta et al. 2018), and nearshore bathymetry (Holman and Haller 2013; Bergsma et al. 2016; Bergsma and Almar 2018; Brodie et al. 2018).

This paper focuses on the capacity of shore-based camera and video systems to obtain total sea levels at an open coast. Here, we utilize a celerity-based depth inversion method, conventionally used to derivate bathymetry, to obtain time-varying depth, which under certain assumptions can provide a measure of total sea levels. We present a comparison of video-derived water levels with tide gauges and spaceborne altimetry at Grand Popo beach in Benin, Gulf of Guinea, over a period from February 2013 to August 2016.

\section{Materials and methods}

\section{a. Study site}

Grand Popo beach (Fig. 1) is located in the Gulf of Guinea, Benin, near the border with Togo. It is an open sandy beach with a modal state between intermediate low-tide terrace (LTT) and reflective beach (Abessolo Ondoa et al. 2017), according to the classification of Wright and Short (1984). The beach faces the South Atlantic Ocean and it is typically exposed to obliquely incident waves [annual-mean significant wave height $(\mathrm{Hs})=1.36 \mathrm{~m}$; mean peak period $(\mathrm{Tp})=$ $9.4 \mathrm{~s}$; south-southwest incidence] that drive an easterly longshore sediment transport of approximately $500000 \mathrm{~m}^{3} \mathrm{yr}^{-1}$. The wave regime can be separated into two primary components: a dominant long-period swell component originating from mid- to high latitudes $\left(45^{\circ}-60^{\circ}\right)$ in the South Atlantic and southwesterly wind seas, locally generated in the tropical band $\left(6^{\circ} \mathrm{N}-15^{\circ} \mathrm{S}\right)$ (Almar et al. 2015). Tides are semidiurnal with a tidal range of approximately 0.3 and $1.8 \mathrm{~m}$ for neap and spring tides, respectively. Grand Popo beach is also characterized by a seasonal variability of sea level in response to wind-driven basin modes involving Kelvin and Rossby wave propagation and reflection (Ding et al. 2009). Intraseasonal sea level fluctuations show amplitude of approximately $0.1 \mathrm{~m}$ while seasonal fluctuations are approximately $0.2 \mathrm{~m}$ (Polo et al. 2008). The sediment size is medium to coarse sand, from 0.4 to $1 \mathrm{~mm}$, with a median grain size $($ D50) $=0.6 \mathrm{~mm}$. 


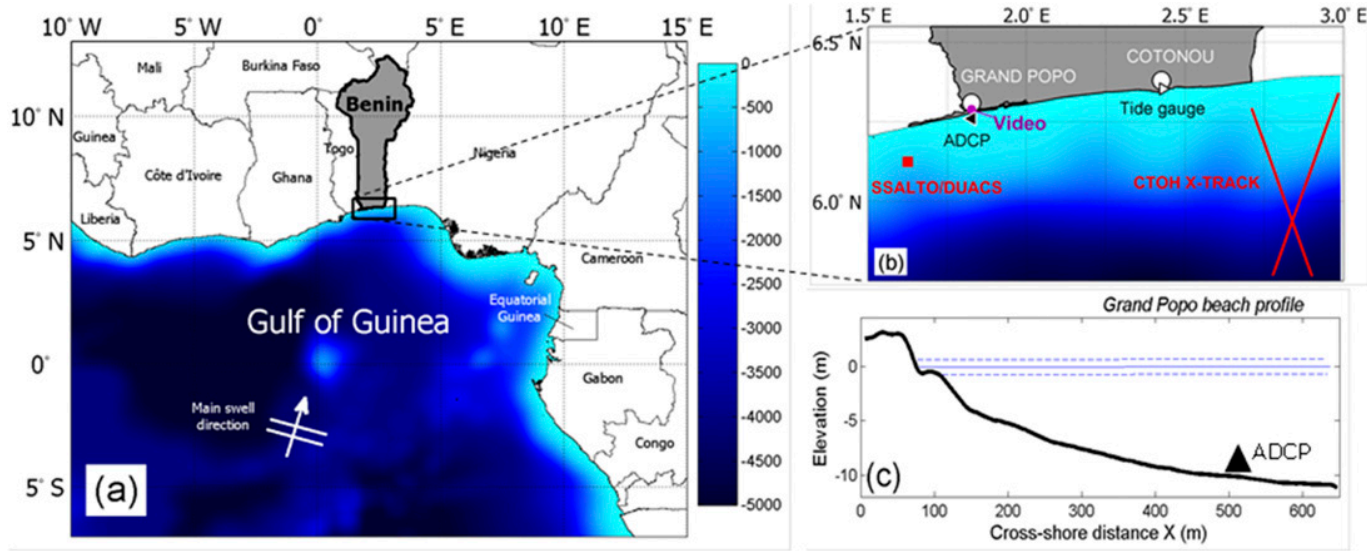

FIG. 1. (a) Study site in Benin, West Africa, Gulf of Guinea, facing the South Atlantic Ocean. The color bar gives the bathymetry (m). (b) Zoom on Benin coast with the nearest tracks of the satellite missions in red (CTOH $\mathrm{X}$-TRACK), extraction node for merged SSALTO/DUACS products, tide gauge at Cotonou harbor, ADCP, and video system at Grand Popo beach. (c) Average beach profile (solid black line) obtained during the Grand Popo experiment (11-20 Mar 2014), with mean sea level (solid blue line) and high and low (blue dashed blue lines) tide levels.

\section{b. Data}

\section{1) VIDEO DATA}

In February 2013, a low-cost video system was installed on a 15-m-high tower located approximately $70 \mathrm{~m}$ from the shoreline (Almar et al. 2014). A VIVOTEK IP 7361 camera $(1600 \times 728$ pixels $)$ continuously collects data at a $2-\mathrm{Hz}$ framerate between 0700 and 1700 local time. An on-site computer processes the raw image-frames and stores 15-min time-stack images (Aagaard and Holm 1989; Holland and Holman 1993) by stacking the successive traces corresponding to $15 \mathrm{~min}$ of snapshots, with as many 15-min time-stack images as traces implemented. Among the available traces, only one is cross-shore to the coast and therefore, was chosen for this pioneering study (Fig. 2b). The dataset used here covers 792 days during 3.5 years between February 2013 and August 2016, which represents $61.4 \%$ of days over the study period. Missing data are due to temporary malfunctions of the camera or poor quality of the images collected. The temporary malfunctions of the camera could be avoided with adequate maintenance protocols, but the poor quality of the images depends on atmospheric conditions such as the dew on the lens of the camera, fog, and sunlight. A simple criterion based on image intensity was used to select the images relevant for processing. Andriolo (2018) showed that pixel intensity brightness on a time-stack image characterizes the wave transformations domains. The criterion was computed with the standard deviation of the pixel intensity along the time axis of the time-stack image for the blue color band. The blue color band represents better both shoaling and breaking waves (Andriolo 2018). Specific local maxima, corresponding to breaking area, in the standard deviation of pixel intensity validate good image quality. Otherwise, the image is rejected. In addition, the video system does not acquire any information during the night. However, all these data gaps are considered to have a minor effect on the analysis presented here.

Georeferencing and rectification from image pixels into real-world coordinates is accomplished by direct linear transformation (Holland et al. 1997) using 20 differential global positioning system (DGPS) ground control points and radial distortion correction of the lens (Heikkila and Silven 1997). The origin $(X=0)$ of the positive seaward (south) cross-shore coordinate $X$ corresponds to the camera location, whereas the vertical origin $(Z=0)$ refers to mean sea level (MSL; Fig. 1c). The chosen cross-shore stack extends approximately $715 \mathrm{~m}$. Using the ground control points located on the beach, the average horizontal error of the rectification method is $3 \mathrm{~m}$. In addition, given the oblique angle of view of the camera, the cross-shore pixel footprint $\Delta X_{0}$ increases seaward, ranging from $\sim 0.05 \mathrm{~m}$ on the beach to approximatively $10 \mathrm{~m}$ offshore. The footprint $\Delta X_{0}$ remains consistently smaller than $1 \mathrm{~m}$ in our area of interest, which corresponds approximately to the region extending from the MSL shoreline seaward to the nearshore profile at 8-m depth. We assume that the overall horizontal error is smaller than $5 \mathrm{~m}$ within the domain of interest. 

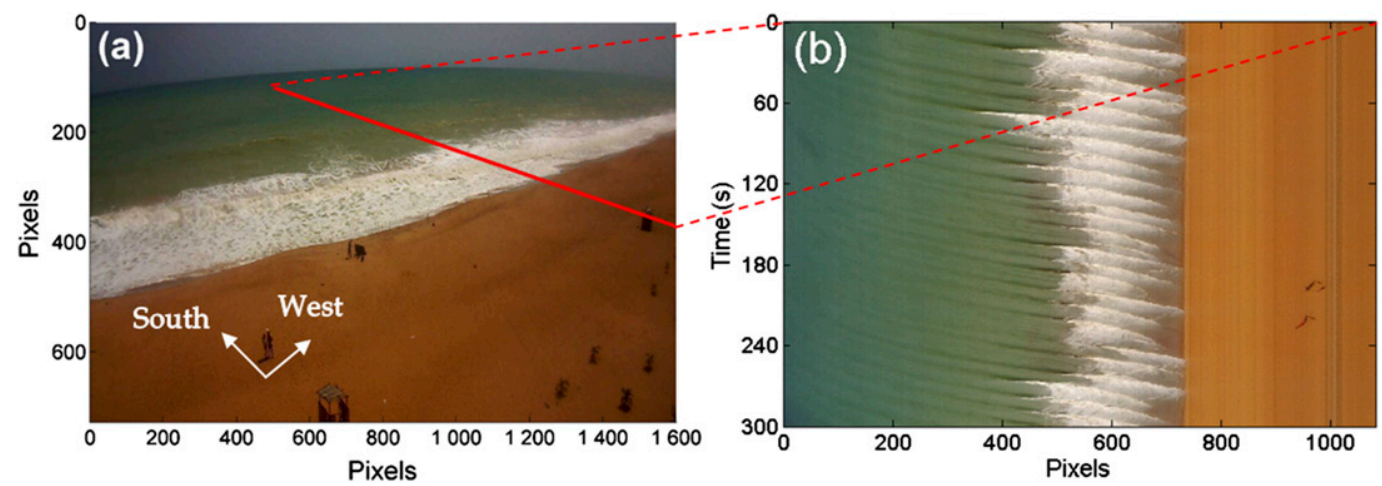

FIG. 2. Stored video images: (a) video snapshot (cross-shore time-stack location in red) and (b) time-stack image obtained for $5 \mathrm{~min}$.

\section{2) Field DAtA}

A 10-day field experiment was conducted at Grand Popo from 10 to 19 March 2014 (Abessolo Ondoa et al. 2016) to provide insight into primary beach-change driving processes at this site. Measurements included topography and bathymetry surveys with a DGPS and an echo sounder, respectively. The water column height was measured every $40 \mathrm{~min}$ by an acoustic Doppler current profiler (ADCP) moored in 10-m water depth and measuring in mode surface tracking mode, from 11 to 18 March 2014. The tide was extracted by removing the average column height from the ADCP measurements and interpolated on the video frequency $(15 \mathrm{~min})$.

\section{3) Altimetry}

Sea level time series were extracted from two altimetry products: the "Center for Topographic Studies of the Ocean and Hydrosphere $(\mathrm{CTOH})$ along-track sea level anomalies" provided by CTOH/LEGOS, version X-TRACK 2017 and the SSALTO/Data Unification and Altimeter Combination System (DUACS) multimission gridded and delayed-time products provided by Copernicus Marine and Environment Monitoring Service (CMEMS). Tide, inverse barometer and atmospheric wind are corrected for in both altimetry products. The CTOH X-TRACK sea level time series are obtained from along-track combined TOPEX/Poseidon, Jason-1, Jason-2, and Jason-3 missions, at a spatial resolution of $6-7 \mathrm{~km}$ (Birol et al. 2017). According to the study period (from February 2013 to August 2016), only the Jason-2-derived sea level time series were considered. In the SSALTO/DUACS products, two available altimeter missions are merged and mapped daily onto a $1 / 4^{\circ}$-resolution grid (Pujol et al. 2016; Arbic et al. 2012; Tran et al. 2010; Amarouche et al. 2004). Knowing that this study focuses on the sea level at the coast, both altimetry data were extracted as close as possible to the coast and to the video camera location. CTOH X-TRACK sea level time series were extracted on the track 122 , at the location $6.314^{\circ} \mathrm{N}, 2.714^{\circ} \mathrm{E}$, approximately $98 \mathrm{~km}$ away from the camera and $9 \mathrm{~km}$ off the coast. SSALTO/DUACS time series of sea level were extracted at the grid node $6.125^{\circ} \mathrm{N}, 1.625^{\circ} \mathrm{E}$, approximately $28 \mathrm{~km}$ away from the camera and $12 \mathrm{~km}$ off the coast (Fig. 1b). The extracted data were then averaged monthly, because of the different sampling frequencies of these altimetric products (CTOH X-TRACK 10-day periodicity and SSALTO/DUACS 1-day periodicity).

\section{4) Tide Gauge And Forecasting}

In situ tide data were collected by the tide gauge located at Cotonou harbor $\left(6.33^{\circ} \mathrm{N}, 2.42^{\circ} \mathrm{E}\right)$ with a 5 -min acquisition period from June 2011 to March 2015. The tide gauge is approximately $80 \mathrm{~km}$ away from the camera location. Considering several malfunctions of the tide gauge, available data were processed for 2 years (February 2013-January 2015) and interpolated on the video frequency (15 min).

The Finite Element Solution (FES) 2014 (FES2014) tidal atlas is the latest release of the FES atlas series (Carrere et al. 2016). The FES2014 atlas performance has been assessed and validated with tide gauges and various geophysical applications (satellite altimetry corrections, gravimetry, etc.). It shows significant improvements compared to previous FES releases and other state-of-the-art tidal atlases (Lyard et al. 2016; Ranji et al. 2016). Hourly tidal estimates were extracted from FES2014 from February 2013 to August 2016 and interpolated on the video frequency $(15 \mathrm{~min})$.

\section{c. Video data processing}

\section{1) WAVE CELERITY}

After time-stack images are collected, they are pretreated to clean the wave intensity signal. Given that 
the wave climate is characterized by average period of about 9-10 s, a bandpass filter between 0.05 and $0.5 \mathrm{~Hz}$ is used to remove low-frequency and high-frequency noise (Almar et al. 2008). Low-frequency noise can be induced by light fluctuations due to clouds, or any other process with a periodicity greater than $20 \mathrm{~s}$. High-frequency noise can be induced by wind waves or a rapid adjustment of the camera "auto iris," with a periodicity lower than $2 \mathrm{~s}$. To derive the celerity $c_{i j t}$, a celerity-sensing method is applied for each filtered image at time $t$ on pixel $j$ [details can be found in Almar et al. (2008) and Bergsma and Almar (2018)]. For that, a temporal cross-correlation matrix $\mathbf{M}$ was computed at each pixel $j$ with the neighboring pixel $k$,imposing an arbitrary (but lower than half the wave period) time lag $\Delta t=3 \mathrm{~s}$ (Almar et al. 2008):

$$
\mathbf{M}(j, k)=\operatorname{cor}\left[\eta\left(j, t_{1: n t}\right), \eta\left(j+k, t_{1: n t}+\Delta t\right)\right], \quad k=1,200 .
$$

The index $k_{\max }$ with the maximum correlation gives an estimate of the time-integrated distance $\Delta X$ made by waves during $\Delta t$,

$$
\Delta X=\sum \Delta X_{0}(p), \quad p=j+1, j+k_{\max } .
$$

The pixel footprint $\Delta X_{0}$ depends on the pixel location. A local estimate of the celerity at pixel $j$ at time $t$ is

$$
c_{j t}=\Delta X / \Delta t
$$

\section{2) DEPTH INVERSION}

The depth inversion scheme is based on the linear dispersion relation for free surface waves, which requires two of the three free variables (wavelength $L$, wave period $T$, and wave celerity $c$ ) to be solved (Bergsma and Almar 2018), and reads as

$$
c_{j t}^{2}=\left(g L_{j t} / 2 \pi\right) \tanh \left(2 \pi h_{j t} / L_{j t}\right)+U^{2}\left(2 \pi / L_{j t}\right)^{2} .
$$

The wave celerity $c_{j t}$ is obtained as described in the previous section and the wavelength is given by $L_{j t}=T c_{j t}$, where $T$ is estimated using video intensity time series. The variable $U$ represents the mean current and can be neglected on wave-dominated beaches, as suggested by Bergsma and Almar (2018) for open beaches. The iterative convergence scheme used to derive instant depths $h_{j t}$ associated with the pixel $j$ at time $t$ was described in Almar et al. (2008).

Importantly, the relation between wave celerity and water depth [Eq. (5)] is only valid in intermediate to shallow water depths, that is, in practice for depths $<L / 2$, where $L$ is the wavelength. In the surf zone, the validity of the linear dispersion relation is limited by the increasing degree of nonlinearity (Catalan and Haller 2008; Tissier et al. 2015) as waves approach the shore (Bergsma and Almar 2018). Abessolo Ondoa et al. (2017) obtained a quadratic error of $0.1 \mathrm{~m}$ on the terrace and approximatively $2 \mathrm{~m}$ offshore, corresponding to $10 \%$ of the local depths during the Grand Popo 2014 field campaign.

\section{3) WATER-LEVEL ESTIMATION}

The littoral zone is defined as the part of the beach profile where sediment can be transported by wave action (Davidson-Arnott 2010). On longer time scales (e.g., week, month, year), bathymetry changes significantly, but here, we assume little and negligible morphological change over a single day. Contrary to the conventional use of video-derived depth for bathymetry estimation, we consider here that the instant-derived depth $h_{j t}$ can be separated between the bathymetry $D_{j t}$ and total sea level $\left(\mathrm{SL}_{j t}\right)$, (Thuan et al. 2019):

$$
h_{j t}=D_{j t}+\mathrm{SL}_{j t} .
$$

Thus, any change in $h_{j t}$ over a day in the littoral zone is associated with $\mathrm{SL}_{j t}$ changes, while changes on longer time scales could be associated with both $D_{j t}$ and $\mathrm{SL}_{j t}$. Beyond the littoral zone, where there is no significant transport of sediment by wave action, $D_{j t}$ can be assumed to be constant for longer periods, as there are little changes in bottom elevation. The limit between the two areas can be defined using the depth of closure (DoC) as defined by Kraus et al. (1998) and Hallermeier (1983). Then the video-derived water levels $\mathrm{SL}_{j t}$ at pixel $j$ and time $t$ are obtained by removing the daily average from instant depths $h_{j t}$. The daily average is computed with $6.5 \mathrm{~h}$ of continuous instant depths $h_{j t}$ over a day, to cover a high and a low tide.

It remains difficult to fully discriminate all contributions [Eq. (1)] from video-derived water levels $\left(\mathrm{SL}_{j t}\right)$ without additional assumptions. On the spatial scale of this study (100-200 $\mathrm{m}$ in the cross-shore direction), tidal (AT) and sea level anomaly (SLA), combined with inverse barometer (DA), are supposed to be constant across the whole profile, while wave contribution (i.e., setdown/setup) is varying in the cross-shore direction. The quantities AT and SLA + DA can be extracted using a spatial median averaged of $\mathrm{SL}_{j t}$ over a chosen area on the profile, which is selected using the maximum correlation between $\mathrm{SL}_{j t}$ and field/altimetry data. The median is used to limit the effect of any single value that is too high or too low compared to the 
rest of the estimates. The derived time series are filtering over $2 \mathrm{~h}$, and a spatially constant contribution, representing a "clean" video-derived tide (AT), is obtained. This video-derived tidal signal is compared to the tide derived from ADCP, Cotonou tide gauge and FES2014 data. The Cotonou tide gauge and FES2014 data are interpolated on video time points (15-min period). The video-derived SLA + DA is derived by daily or monthly averaging the $\mathrm{SL}_{j t}$ and is used to perform the comparison with altimetry. The DA is removed from video estimates by applying the same corrections used in CTOH X-TRACK processing (Birol et al. 2017). The obtained monthly averaged SLA is compared to the monthly averaged altimetry data.

The harmonic analysis of the video-derived water levels is performed using the Python version of the Utide software (Codiga 2011). The tidal regime estimated from the nearby Cotonou tide gauge is semidiurnal with four constituent amplitudes greater than $10 \mathrm{~cm}\left(\mathrm{M}_{2}, \mathrm{~S}_{2}, \mathrm{~K}_{1}, \mathrm{~N}_{2}\right)$. After some tests, we focus our analysis on the main semidiurnals and diurnal constituents $\left(\mathrm{M}_{2}, \mathrm{~S}_{2}, \mathrm{~N}_{2}, \mathrm{~K}_{2}, \mathrm{~K}_{1}, \mathrm{P}_{1}, \mathrm{O}_{1}\right)$.

The data processing scheme is presented in Fig. 3, as a synopsis of all processing applied to derive the total coastal sea level from video images.

\section{Results}

\section{a. Video-derived water levels along the beach profile}

The different water-level components (AT and SLA + DA) are estimated most accurately depending on the cross-shore position as illustrated in Fig. 4 (blue-shaded zones). The correlation coefficients between $\mathrm{SL}_{j t}$ and field/altimetry data reveal two main areas at which a high correlation of tide and sea level anomaly can be found. The first area shows that videobased estimation of the tidal constituents is most adequate on the terrace. This holds under the assumption that little changes of $D_{j t}$ occur over a day, unlike longer periods. The second area corresponds to the zone beyond the DoC (Hallermeier 1983), without morphological changes over longer periods of time. Then $D_{j t}$ may not change when addressing long-term SLA from video. Areas with low correlation coefficients on the profile correspond to the surf zone, the incipient breaking zone, and deep water. Thuan et al. (2019) presented a full description of the associated errors for the use of video-based depth inversion methods, which are observed to be low where AT and SLA are derived (see Fig. 10 in Thuan et al. 2019).

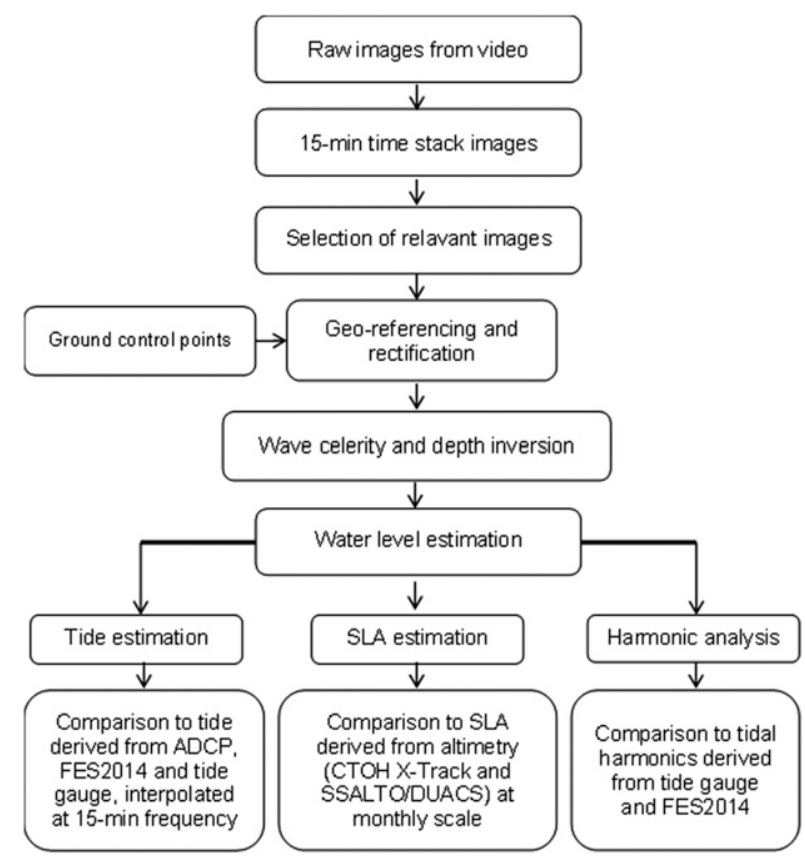

FIG. 3. Data processing scheme.

\section{b. Comparison of the video-derived tide with field measurements and model}

The video-derived tide (AT) is computed on the terrace: $90<X<115 \mathrm{~m}$. From Fig. 4 , we can see that the video-derived tide (on the terrace) and tide derived from ADCP have correlation coefficients greater than 0.5. Figure 5 shows the intercomparison of the video-derived tide with the tide derived from ADCP, Cotonou tide gauge, and FES2014 model data. Table 1 gives corresponding correlation coefficients and rootmean-square (RMS) differences. During the 10-day Grand Popo 2014 field experiment (Fig. 5a), the best agreement between video estimates and ADCPderived tides is found during the last days of the experiment. Important differences (approximatively $30 \mathrm{~cm}$ ) are observed during the first three days, which could be related to local atmospheric and oceanic conditions.

\section{c. Comparison of video-derived sea level anomaly with altimetry}

The correlation coefficients of the SLA are found to be high $(r \geq 0.5)$ at depths greater than $4 \mathrm{~m}: 170<$ $X<230 \mathrm{~m}$ (Fig. 4). This cross-shore range is beyond the depth of closure and hence we can presume that $D_{j t}$ is constant on a monthly scale. Also, any temporal variation of the total water level is driven by the SLA + DA components. Figure 6 shows the monthly video-derived anomalies SLA compared to 


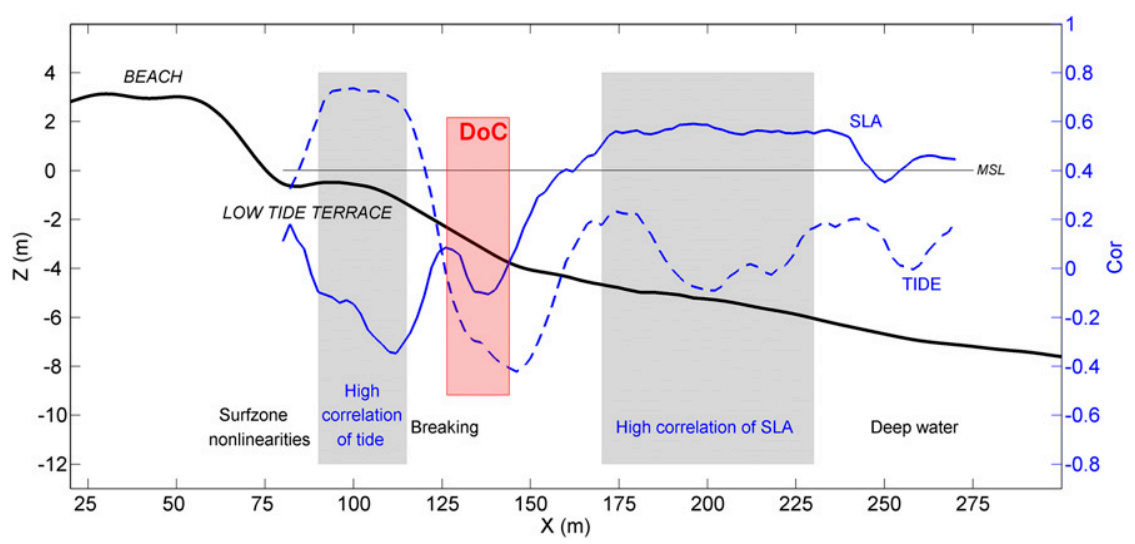

FIG. 4. Evolution of the correlation coefficients between video and field/altimetry data: Dashed blue line shows the correlation between 2-h-smoothed $\mathrm{SL}_{j t}$ and ADCP measurements, and solid blue line represents the correlation between monthly averaged $\mathrm{SL}_{j t}$ and SSALTO/DUACS data. Red shaded area indicates the depth of closure (DoC) variation zone.

monthly SSALTO/DUACS and CTOH X-TRACK sea level anomalies. Table 2 shows the corresponding correlation $r$, RMS difference, and $p$ value. It is observed that the video-derived SLA is overall consistent with altimetry products. The three sets of data show the same seasonality, as shown by the correlation values. However, computed RMS differences correspond to $25 \%$ of the sea level anomaly and some discrepancies can be observed between video and altimetry. Also, the 3.5-yr video data are not long enough to derive the sea level anomaly trend in the study area.

\section{d. Comparison of long-term video-derived tidal harmonics components with field data}

Figure 7 shows the main tidal constituents for the Gulf of Guinea subregion derived from the videoderived tide, the FES2014 model, and the Cotonou gauge data. It is observed that the video signal well represents the amplitudes of the main semidiurnal
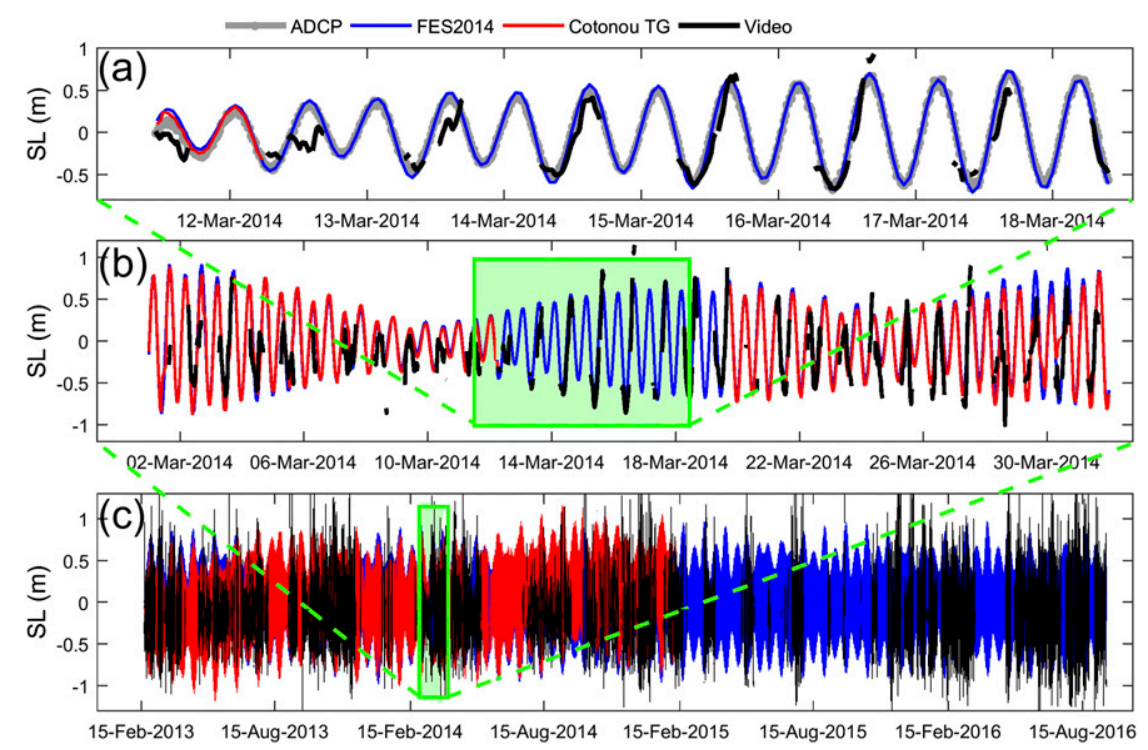

FIG. 5. Comparison of video-derived water levels with time series of tide derived from the ADCP, the Cotonou tide gauge, and the FES2014 model. (c) Time series over the study period. (a),(b) Zooms of the time series over the 10-day Grand Popo 2014 field experiments and the month of March 2014, respectively. 
TABLE 1. Correlations $r$ and RMS differences in video-derived tide AT with the time series of tides derived from the ADCP, Cotonou tide gauge, and FES2014 model. All correlations were obtained with $p$ value $<10^{-2}$.

\begin{tabular}{lccc}
\hline \hline & ADCP & Cotonou tide gauge & FES2014 \\
\hline Dates & 11-18 Mar 2014 (10 days) & February 2013-January 2015 & February 2013-August 2016 \\
$r$ & & (2 years) & (3.5 years) \\
RMS difference (m) & 0.90 & 0.58 & 0.64 \\
\hline
\end{tabular}

and diurnal tidal constituent. The observed differences in the amplitude of tidal harmonics are likely due to other contributions than tides such as waves, interdaily morphological changes, local forcing in the coastal area, with interdependence between the various temporal scales, and the errors from the videoderived method.

\section{Discussion}

\section{a. Errors on celerity estimation and depth inversion}

The method presented in this work relies on the precision in the estimation of wave celerity and depth. During the 10-day experiment of Grand Popo (11-20 March 2014), the overall inaccuracies were estimated to be around $10 \%$ of the local depths (Abessolo Ondoa et al. 2017). This error is likely to vary over the total length of the study period (2013-16) according to the main source of errors investigated by Bergsma and Almar (2018). Their results show that the main source of errors can be related to the limited validity of the linear dispersion relation in the shallowest parts of the near shore. As waves shoal, break, and become nonlinear, implementation of linear wave theory may be inaccurate near the shoreline (Brodie et al. 2018).

In addition, Bergsma et al. (2016) showed that videoderived wave celerity may be biased by presuming a fixed free water surface level, while in fact, the water surface alternates with the tide. The fluctuations of the water surface with the tide change the geographical pixel locations and thus modify the estimated timeintegrated distance $\Delta X$. Bergsma et al. (2016) showed that the associated error depends on the local videosystem settings, such as camera height and distance from the camera in combination with the tidal range. At Grand Popo, the rectification was done at mean tide level and this effect leads to a horizontal pixel displacement of $3-25 \mathrm{~m}$, according to the formulation proposed by Bergsma et al. (2016). This might add an error of $0.2-1 \mathrm{~m}$ to the depth estimation for a $0.01-0.05$ bottom slope. Thus, this error may be large where the bottom slope is steep. The camera viewing angle also introduces an error related to the pixel footprint increasing offshore. Although this error has been estimated at less than $1 \mathrm{~m}$ in the area of interest, its impact on depth inversion scheme has not yet been assessed. Camera movements are another source of error in the image rectification process (Bouvier et al. 2019), but camera movements at Grand Popo were deemed small and with no influence on the area of interest where wave information was inferred.

Interestingly, even if reducing these errors is challenging (Brodie et al. 2018), their effect can be overcome through assimilation. Following Bergsma and Almar (2018), a quality criterion can be defined by comparing the celerity obtained with Eq. (4) and that obtained with $c_{0 j t}=L_{0 j t} / T$.

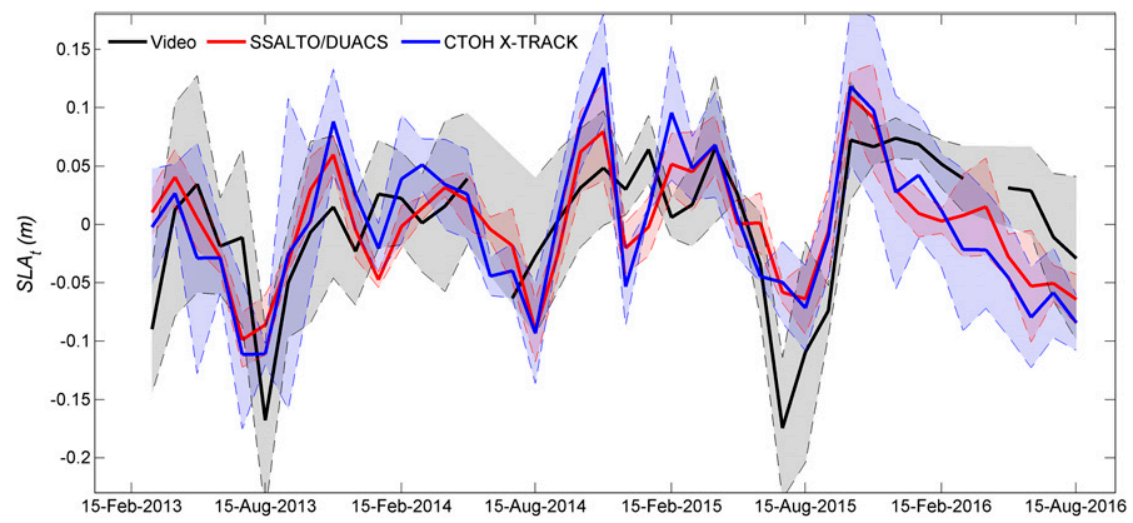

FIG. 6. Comparison of video (black), SSALTO/DUACS (red), and CTOH X-TRACK (blue) monthly derived sea level anomalies. Shaded areas indicate the day-to-day dispersions. 
TABLE 2. Correlations $r$ and RMS differences between monthly video-derived water-level anomalies with monthly CTOH X-TRACK and monthly SSALTO/DUACS sea level anomalies.

\begin{tabular}{lcc}
\hline \hline & CTOH X-TRACK & SSALTO/DUACS \\
\hline$r$ & 0.56 & 0.58 \\
RMS difference $(\mathrm{m})$ & 0.06 & 0.05 \\
$p$ value & $1.8 \times 10^{-4}$ & $0.9 \times 10^{-4}$ \\
\hline
\end{tabular}

The wavelength $L_{0 j t}$ represents an estimated value at position $j$ on the stack at time $t$, equivalent to twice the distance between the maximum and the minimum of the intercorrelation on a time-stack image (see Fig. 1 in Bergsma and Almar 2018). Another criterion can be associated with the difference between tides derived from video and tides derived from another device (tide gauge) or model. Thuan et al. (2019) showed that the computed differences are generally consistent with breakpoint error and nonlinear effects during shoaling and in shallow water. The use of such criteria might result in a substantial improvement of the methodology presented in this paper when looking for areas on the profile where the celerity detection error is low.

\section{b. Limitations and errors on water level}

\section{1) Limitations}

Equation (6) suggests that the derived instant water depth $h_{j t}$ can be separated into contributions due to bathymetry $D_{j t}$ and total sea level $\left(\mathrm{SL}_{j t}\right)$. This means that errors associated with bathymetry may differ from errors associated with water-level variations (AT and SLA + DA). Because of this complexity, it remains difficult to directly estimate the error in the videoderived water levels, since bathymetry changes may affect video-derived water levels.

The validation of the video-derived water levels is also an issue. For that, it would have been necessary to have more frequent measurements of water level and bottom elevation on the cross-shore profile over a longenough time period to allow for water-level estimations/calculations at different time scales. It would have required the deployment of pressure sensors or the use of remote sensing equipment, such as the lidar, covering the field of view of the camera (Brodie et al. 2018). Such data are generally rare and nonexistent at our study site. Altimetry data are available more than $9 \mathrm{~km}$ off the coast, whereas tide gauge data have been measured approximately $80 \mathrm{~km}$ away from the camera location, and the ADCP data are limited to a 10-day observation. In addition, magnitude of wave propagations and their impact on video estimates of

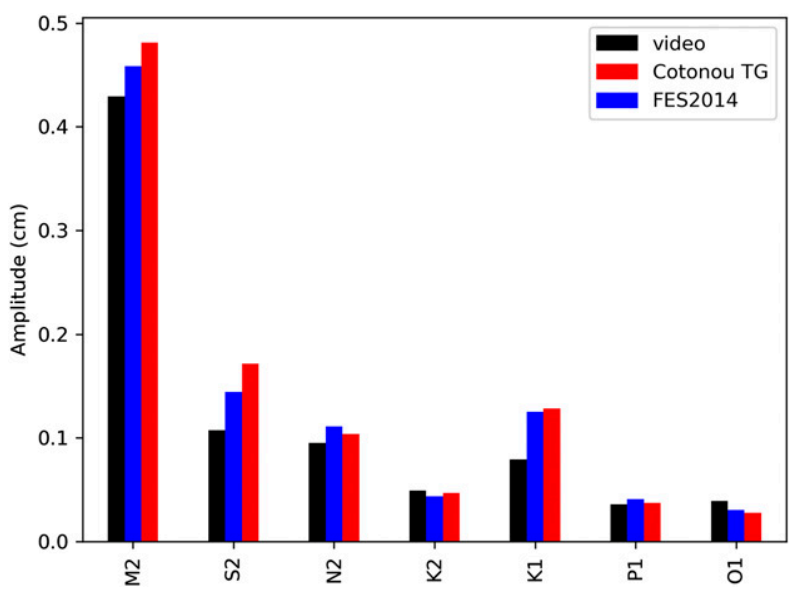

FIG. 7. Tidal constituents derived with the Python version of the Utide software from video (black), Cotonou tide gauge (red), and FES2014 (blue) data.

total sea levels are also difficult to assess, because of the lack of buoys in the study site during the study period. Furthermore, video estimation, tide gauge, and altimetry products do not incorporate the same processes nor measure at the same time scales and in the same place. This approach should, therefore, be replicated in other more instrumented sites.

Although the video gives information measured directly on the coast (0-1 km offshore) with a 15 -min frequency, one of the main limitations is its inability to measure at night.

\section{2) ERRors ON TIDE ESTIMATION}

The video-derived tide (AT) is assumed to be constant over the cross-shore beach profile, whereas wave $W$ and wind (Wi) are affected by wave nonlinearities in the nearshore (surf zone) environment (Bergsma and Almar 2018; Brodie et al. 2018). Since AT is derived on the terrace using a cross-shore median averaged of $\mathrm{SL}_{j t}$, separating the $W$ and Wi contributions from AT is challenging. In addition, AT is derived over a cross-shore area at which we can assume that morphological evolution is negligible over a day. However, wave-exposed coasts that often experience extreme events are prone to rapid bathymetric changes. This leads to substantial variations in the video-derived tide (AT) over a day. The RMS differences in AT estimations can be related to $W+$ Wi contributions during moderate wave conditions and to $W+\mathrm{Wi}$ contributions associated with bathymetry changes during extremes events. A typical example of differences on the order of $30 \mathrm{~cm}$ is observed during the first 3 days of the Grand Popo 2014 field experiment. The video RMS difference for the field data represents an average error on the order of $20 \%$ of the tide 
(Table 1). The sum AT $+W+$ Wi contributes to the total sea level, whereas the bathymetry changes, wave nonlinearities, and wave breaking in the near shore lead to uncertainties in the total sea level at the coast. Thus, AT $+W+$ Wi may be derived more accurately in environments in which bathymetric changes are limited (rocky beaches) and/or relatively slow under moderate wave conditions.

\section{3) ERrors on SLA ESTIMATION}

At depths greater than the DoC, the contributions of bathymetry changes to the total sea level are assumed to be negligible. Kraus et al. (1998) provided a definition of the DoC, based on the available literature, as the depth beyond which there is no significant change in bottom elevation. At such a location, the error on the SLA estimation may be related to the wave celerity and inversion error described by Bergsma and Almar (2018). In addition, gaps in the video data within a month will affect the monthly averaged values. This is not only the case for video. CTOH X-TRACK data are limited to one sample approximatively every 10 days while SSALTO/DUACS data were reinterpolated daily from available satellite tracks with several days of periodicity. These three data sources show the same seasonality and must be used in complementarity in order to avoid the problem of data gaps due to the different measuring time scales. The differences identified could also be explained by the nonlinearities at the coast. Likewise, separating $W$ and Wi contributions from SLA + DA is challenging. The video RMS difference with altimetry data represents an average error on the order of $25 \%$ of the sea level anomaly (Table 2).

\section{c. Potential of video coastal network: Ground truth for spatial studies and early warning systems}

There is a clear need to understand sea level propagation in the near shore. The results obtained in this study show that video systems have good skills in observing sea level variability at the event and monthly scales. It is a low-cost technique suitable for nearshore areas where the installation of traditional measuring devices turns out to be difficult and expensive. Nonetheless, there are still some parts of the method that can be improved, since the computed RMS differences with field/altimetry data remain high compared to the errors of other conventional devices. However, the technique is promising, regarding the complexity of nearshore areas.

Altimetry products have great difficulty measuring close to the coast. Marti et al. (2019) investigated the rate of sea level change, combining ALES retracked altimetry data (Passaro et al. 2018a,b) and geophysical corrections dedicated to coastal areas (Birol et al. 2017). The obtained X-TRACK/ALES $20-\mathrm{Hz}$ products allow to get a little closer to the coasts (up to $3 \mathrm{~km}$ ), but not so close to observe wave undergoing transformations within depths of less than $10 \mathrm{~m}$. The impact of wave transformations on sea level is still poorly understood and validated, as tide gauges are limited to sheltered places (Melet et al. 2016, 2018). The challenge remains on understanding waves effects in new radar gauges measurements. Shore-based video systems can, therefore, be used to supplement existing tide gauges and altimetry. Combining the future French-U.S. SWOT (for example) mission to the video-based estimation of water levels opens the possibility to address and fill in the existing knowledge gap between deep and coast waters: $0-1 \mathrm{~km}$ from the coast with video and $1-10 \mathrm{~km}$ with new and future altimetry products.

Video-derived water levels can be used to investigate processes related to storm surge and coastal flooding while supporting high-frequency and localized validation of wave forecasts and reanalysis of ocean forcing. Moreover, video capabilities can be used for longer periods of time, providing long-term coastal waterlevel time series in order to validate the method to estimate the coastal contribution to water levels proposed by Melet et al. (2018) or Anderson et al. (2018). A regional network of video cameras along the West African coast, for example, would densify the waterlevel monitoring network at long-term time scale. It could be the backbone of a real-time, early-warning system for coastal disasters, as shown in Sembiring et al. (2017).

\section{Conclusions}

In this study, we present a novel method to measure total sea level at the coast using for the first time a shore-based video-monitoring system. For the case study in Grand Popo, Benin (Gulf of Guinea), video-derived water levels showed similar characteristics with (i) 10-day field data: $r=0.9$, RMS difference $=$ $0.2 \mathrm{~m}$; (ii) 2 -yr tide gauge data $80 \mathrm{~km}$ far away: $r=0.58$, RMS difference $=0.38 \mathrm{~m}$; and (iii) 3.5 -yr altimetry products: SSALTO/DUACS $r=0.58$, RMS difference $=0.05 \mathrm{~m}$; CTOH X-TRACK samples: $r=$ 0.56 , RMS difference $=0.06 \mathrm{~m}$. The most important tidal harmonics $\left(\mathrm{M}_{2}, \mathrm{~S}_{2}, \mathrm{~K}_{1}, \mathrm{~N}_{2}, \mathrm{~K}_{1}, \mathrm{P}_{1}\right.$, and $\left.\mathrm{O}_{1}\right)$ are well estimated from the video. Therefore, this novel approach to derive the total sea level at the coast from video (i) is particularly (with greater certainty) suitable for environments in which bathymetric changes are 
limited (rocky beaches) and/or relatively slow under moderate wave conditions and (ii) should be used at cross-shore positions where waves and wind nonlinearity errors are low. This pioneering study highlights the potential of low-cost video cameras in observing sea level at the coast. Furthermore, combining future altimetry products with observations of the total sea level at the coast derived from shore-based video systems would give new insights to close the knowledge gap from the continental shelf to the coast.

Acknowledgments. This publication was made possible through support provided by the French Institute of Research for Development (IRD). The authors are grateful to the Center for Topographic studies of the Ocean and Hydrosphere (CTOH) at LEGOS (Toulouse, France) for providing the altimetry X-TRACK dataset (http://ctoh.legos.obs-mip.fr/products/coastal-products/ coastal-products-1/sla-1hz; https://doi.org/10.6096/CTOH_ X-TRACK_2017_02). Thanks are due to Florent Lyard for providing FES2014 tidal data, to Habib Dieng for downloading COPERNICUS SSALTO/DUACS products (http://marine.copernicus.eu/services-portfolio/ access-to-products), and to Gaël Alory, Remy Chuchla, and Yves du Penhoat for their technical support in maintaining the video system of Grand Popo, Benin. We thank the Institut de Recherche Halieutique et Océanologique du Bénin (IRHOB) and the "Port Autonome de Cotonou" for providing video and tide gauge data. The Grand Popo experiment was supported by the French INSU/CNRS EC2CO-LEFE/ IRD, IRHOB, and UNESCO Co-Chair ICMPA/ UAC. We are indebted to the "Forces Navales" of Benin at Grand Popo for their logistic support during the field experiment and for allowing the installation of the permanent video system on the semaphore. We would like to express our gratitude to JEAIRELIFOME (Young Research Team associated to IRD) for its financial and technical support. The authors declare no conflict of interest.

\section{REFERENCES}

Aagaard, T., and D. Holm, 1989: Digitization of wave runup using video records. J. Coastal Res., 5, 547-551.

Abessolo Ondoa, G., and Coauthors, 2016: Potential of video cameras in assessing event and seasonal coastline behaviour: Grand Popo, Benin (Gulf of Guinea). J. Coastal Res., 75, 442-446, https://doi.org/10.2112/SI75-089.1.

— , and Coauthors, 2017: Development of a West and Central Africa regional video camera network to monitor coastal response to multiscale ocean forcing. Proc. Coastal Dynamics, Elsinore, Denmark, University of Copenhagen, 1540-1550.

Almar, R., N. Senechal, P. Bonneton, and J. A. Roelvink, 2008: Wave celerity from video imaging: A new method. Proc. 31st
Int. Conf. Coastal Engineering, Hamburg, Germany, American Society of Civil Engineers, 661-673.

, R. Cienfuegos, P. A. Catalan, H. Michallet, B. Castelle, P. Bonneton, and V. Marieu, 2012a: A new breaking wave height direct estimation from video. Coastal Eng., 61, 42-48, https://doi.org/10.1016/j.coastaleng.2011.12.004.

—, R. Ranasinghe, N. Sénéchal, P. Bonneton, D. Roelvink, K. R. Bryan, V. Marieu, and J. P. Parisot, 2012b: Videobased detection of shorelines at complex meso-macro tidal beaches. J. Coastal Res., 28, 1040-1048, https://doi.org/10.2112/ JCOASTRES-D-10-00149.1.

— , and Coauthors, 2014: The Grand Popo beach 2013 experiment, Benin, West Africa: From short timescale processes to their integrated impact over long-term coastal evolution. J. Coastal Res., 70, 651-656, https://doi.org/10.2112/SI70-110.1. , and Coauthors, 2015: Response of the Bight of Benin (Gulf of Guinea, West Africa) coastline to anthropogenic and natural forcing. Part 1: Wave climate variability and impacts on the longshore sediment transport. Cont. Shelf Res., 110, 48-59, https://doi.org/10.1016/j.csr.2015.09.020.

— , S. Larnier, B. Castelle, T. Scott, and F. Floc'h, 2016: On the use of the Radon transform to estimate longshore currents from video imagery. Coastal Eng., 114, 301-308, https:// doi.org/10.1016/j.coastaleng.2016.04.016.

Amarouche, L., P. Thibaut, O. Zanife, J.-P. Dumont, P. Vincent, and N. Steunou, 2004: Improving the Jason-1 ground retracking to better account for attitude effects. Mar. Geod., 27, 171-197, https://doi.org/10.1080/01490410490465210.

Anderson, T. R., C. H. Fletcher, M. M. Barbee, B. M. Romine, S. Lemmo, and J. M. S. Delevaux, 2018: Modelling multiple sea level rise stresses reveals up to twice the land at risk compared to strictly passive flooding methods. Sci. Rep., 8 , 14484, https://doi.org/10.1038/s41598-018-32658-x.

Andriolo, U., 2018: Nearshore hydrodynamics and morphology derived from video imagery. Ph.D. dissertation, Faculty of Sciences, University of Lisbon, 227 pp.

Angnuureng, D. B., R. Almar, K. Appeaning Addo, N. Senechal, B. Castelle, S. W. Laryea, and G. Wiafe, 2016: Video observation of waves and shoreline change on the microtidal James town Beach in Ghana. J. Coastal Res., 75, 1022-1026, https:// doi.org/10.2112/SI75-205.1.

Arbic, B. K., R. B. Scott, D. B. Chelton, J. G. Richman, and J. F. Shriver, 2012: Effects on stencil width on surface ocean geostrophic velocity and vorticity estimation from gridded satellite altimeter data. J. Geophys. Res., 117, C03029, https:// doi.org/10.1029/2011JC007367.

Bergsma, E. W. J., and R. Almar, 2018: Video-based depth inversion techniques, a method comparison with synthetic cases. Coastal Eng., 138, 199-209, https://doi.org/10.1016/j.coastaleng.2018.04.025.

—, D. C. Conley, M. A. Davidson, and T. J. O'Hare, 2016: Videobased nearshore bathymetry estimation in macro-tidal environments. Mar. Geol., 374, 31-41, https://doi.org/10.1016/ j.margeo.2016.02.001.

$[,-,-, \ldots$, and R. Almar, 2019: Storm event to seasonal evolution of nearshore bathymetry derived from shore-based video imagery. Remote Sens., 11, 519, https://doi.org/10.3390/ rs11050519.

Birol, F., and Coauthors, 2017: Coastal applications from nadir altimetry: Example of the X-TRACK regional products. $A d v$. Space Res., 59, 936-953, https://doi.org/10.1016/j.asr.2016.11.005.

Boak, E. H., and I. L. Turner, 2005: Shoreline definition and detection: A review. J. Coastal Res., 214, 688-703, https://doi.org/ 10.2112/03-0071.1. 
Bouvier, C., Y. Balouin, B. Castelle, and R. A. Holman, 2019: Modelling camera viewing angle deviation to improve nearshore video monitoring. Coastal Eng., 147, 99-106, https:// doi.org/10.1016/j.coastaleng.2019.02.009.

Brodie, K. L., M. L. Palmsten, T. J. Hesser, P. J. Dickhudt, B. Raubenheimer, H. Ladner, and S. Elgar, 2018: Evaluation of video-based linear depth inversion performance and applications using altimeters and hydrographic surveys in a wide range of environmental conditions. Coastal Eng., 136, 147-160, https://doi.org/10.1016/j.coastaleng.2018.01.003.

Carrere, L., F. Lyard, M. Cancet, A. Guillot, and N. Picot, 2016: FES 2014, a new tidal model-Validation results and perspectives for improvements. Living Planet Symp., Prague, Czech Republic, ESA.

Catalan, P. A., and M. C. Haller, 2008: Remote sensing of breaking wave phase speeds with application to non-linear depth inversions. Coastal Eng., 55, 93-111, https://doi.org/10.1016/ j.coastaleng.2007.09.010.

Cazenave, A., H. Palanisamy, and M. Ablain, 2018: Contemporary sea level changes from satellite altimetry: What have we learned? What are the new challenges? Adv. Space Res., 62, 1639-1653, https://doi.org/10.1016/j.asr.2018.07.017.

Cipollini, P., F. M. Calafat, S. Jevrejeva, A. Melet, and P. Prandi, 2017: Monitoring sea level in the coastal zone with satellite altimetry and tide gauges. Surv. Geophys., 38, 33-57, https:// doi.org/10.1007/s10712-016-9392-0.

Codiga, D. L., 2011: Unified tidal analysis and prediction using the UTide MATLAB functions. University of Rhode Island Graduate School of Oceanography Tech. Rep. 2011-01, 59 pp., ftp://www.po.gso.uri.edu/pub/downloads/codiga/pubs/ 2011Codiga-UTide-Report.pdf.

Davidson-Arnott, R., 2010: Introduction to Coastal Processes and Geomorphology. Cambridge University Press, 458 pp.

Ding, H., N. S. Keenlyside, and M. Latif, 2009: Seasonal cycle in the upper equatorial Atlantic Ocean. J. Geophys. Res., 114, C09016, https://doi.org/10.1029/2008JD010723.

Elko, N., and Coauthors, Eds., 2014: The future of nearshore processes research. Scripps Institute of Oceanography Rep., 34 pp., https:// scripps.ucsd.edu/centers/nearshorefuture/wp-content/uploads/sites/ 37/2014/12/Future_Nearshore_Processes_Research.pdf.

Hallermeier, R. J., 1983: Sand transport limits in coastal structure design, Proc. Coastal Structures '83, New York, NY, American Society of Civil Engineers, 703-716.

Heikkila, J., and O. Silven, 1997: A four-step camera calibration procedure with implicit image correction: Computer vision and pattern recognition. Proc. IEEE Computer Society Conf., San Juan, Puerto Rico, IEEE, 1106-1112, https://doi.org/ 10.1109/CVPR.1997.609468.

Holland, K. T., and R. A. Holman, 1993: The statistical distribution of swash maxima on natural beaches. J. Geophys. Res., 98, 10 271-10 278, https://doi.org/10.1029/93JC00035.

,$- \ldots$, T. C. Lippmann, J. Stanley, and N. Plant, 1997: Practical use of video imagery in near-shore oceanographic field studies. IEEE J. Ocean Eng., 22, 81-92, https://doi.org/10.1109/48.557542.

Holman, R. A., and J. Stanley, 2007: The history and technical capabilities of Argus. Coastal Eng., 54, 477-491, https:// doi.org/10.1016/j.coastaleng.2007.01.003.

— Rev. Mar. Sci., 5, 95-113, https://doi.org/10.1146/annurevmarine-121211-172408.

Ibaceta, R., R. Almar, P. A. Catalán, C. E. Blenkinsopp, L. P. Almeida, and R. Cienfuegos, 2018: Assessing the performance of a lowcost method for video-monitoring the water surface and bed level in the swash zone of natural beaches. Remote Sens., $\mathbf{1 0}$, 49, https://doi.org/10.3390/rs10010049.

Idzanovic, M., V. Ophaug, and B. Andersen, 2018: Coastal sea level from CryoSat-2 SARIn altimetry in Norway. Adv. Space Res., 62, 1344-1357, https://doi.org/10.1016/j.asr.2017.07.043.

Komar, P., 1998: Beach Processes and Sedimentation. 2nd ed. Prentice Hall, 544 pp.

Kraus, N. C., M. Larson, and R. A. Wise, 1998: Depth of closure in beach-fill design. Coastal Engineering Tech. Note CETN II-40, $14 \mathrm{pp}$.

Lyard, F. H., L. Carrere, M. Cancet, J. P. Boy, P. Gegout, and J. M. Lemoine, 2016: The FES2014 tidal atlas, accuracy assessment for satellite altimetry and other geophysical applications. EGU General Assembly, Vienna, Austria, European Geosciences Union, 17693.

Marti, F., A. Cazenave, F. Birol, M. Passaro, F. Leger, F. J. Beneviste, and J. F. Legeais, 2019: Altimetry-based sea level trends along the coasts of western Africa. Adv. Space Res., https://doi.org/10.1016/j.asr.2019.05.033, in press.

Melet, A., R. Almar, and B. Meyssignac, 2016: What dominates sea level at the coast: A case study for the Gulf of Guinea. Ocean Dyn., 66, 623-636, https://doi.org/10.1007/s10236-016-0942-2.

_ , B. Meyssignac, R. Almar, and G. Le Cozannet, 2018: Under-estimated wave contribution to coastal sea-level rise. Nat. Climate Change, 8, 234-239, https://doi.org/10.1038/ s41558-018-0088-y.

Osorio, A. F., R. Medina, and M. Gonzalez, 2012: An algorithm for the measurement of shoreline and intertidal beach profiles using video imagery: PSDM. Comput. Geosci., 46, 196-207, https://doi.org/10.1016/j.cageo.2011.12.008.

Passaro, M., P. Cipollini, S. Vignudelli, G. D. Quartly, and H.M. Snaith, 2014: ALES: A multi-mission adaptive subwave form retracker for coastal and open ocean altimetry. Remote Sens. Environ., 145, 173-189, https://doi.org/10.1016/j.rse.2014.02.008.

-, M. K. Rose, O. B. Andersen, E. Boergens, F. M. Calafat, D. Dettmering, and J. Benveniste, 2018a: ALES+: Adapting a homogenous ocean retracker for satellite altimetry to sea ice leads, coastal and inland waters. Remote Sens. Environ., 211, 456-471, https://doi.org/10.1016/j.rse.2018.02.074.

_ , N. Zulfikar Adlan, and G. D. Quartly, 2018b: Improving the precision of sea level data from satellite altimetry with high frequency and regional sea state bias corrections. Remote Sens. Environ., 218, 245-254, https://doi.org/10.1016/ j.rse.2018.09.007.

Pianca, C., R. Holman, and E. Siegle, 2015: Shoreline variability from days to decades: Results of long-term video imaging. J. Geophys. Res. Oceans, 120, 2159-2178, https://doi.org/ 10.1002/2014JC010329.

Polo, I., A. Lazar, B. Rodriguez-Fonseca, and S. Arnault, 2008: Oceanic Kelvin waves and tropical Atlantic intraseasonal variability: 1. Kelvin wave characterization. J. Geophys. Res., 113, C07009, https://doi.org/10.1029/2007JC004495.

Pujol, M.-I., Y. Faugère, G. Taburet, S. Dupuy, C. Pelloquin, M. Ablain, and N. Picot, 2016: DUACS DT2014: The new multimission altimeter data set reprocessed over 20 years. Ocean Sci., 12, 1067-1090, https://doi.org/10.5194/os-12-1067-2016.

Radermacher, M., M. E. Wengrove, J. S. M. Van Thiel de Vries, and R. A. Holman, 2014: Applicability of video-derived bathymetry estimates to nearshore current model predictions. J. Coastal Res., 70, 290-295, https://doi.org/10.2112/SI70-049.1.

Ranji, Z., K. Hejazi, M. Soltanpour, and M. Allahyar, 2016: Intercomparison of recent tide models for the Persian Gulf and Oman Sea. Proc. 35th Conf. on Coastal Engineering, Antalya, 
Turkey, Coastal Engineering Research Council, 443-454, https://doi.org/10.9753/icce.v35.currents.9.

Segura, L. E., J. E. Hansen, and R. J. Lowe, 2018: Seasonal shoreline variability induced by subtidal water level fluctuations at reef-fringed beaches. J. Geophys. Res. Earth Surf., 123, 433-447, https://doi.org/10.1002/2017JF004385.

Sembiring, L., M. Van Ormondt, A. R. Van Dongeren, and J. A. Roelvink, 2017: Operational prediction of rip currents using numerical model and nearshore bathymetry from video images. AIP Conf. Proc., 1857, 080004, https://doi.org/10.1063/1.4987098.

Slangen, A. B., and Coauthors, 2017: Evaluating model simulations of twentieth-century sea level rise. Part I: Global mean sea level change. J. Climate, 30, 8539-8563, https://doi.org/ 10.1175/JCLI-D-17-0110.1.

Thuan, D. H., R. Almar, P. Marchesiello, and N. T. Viet, 2019: Video sensing of nearshore bathymetry evolution with error estimate. J. Mar. Sci. Eng., 7, 233, https://doi.org/10.3390/jmse7070233.

Tissier, M., P. Bonneton, H. Michallet, and G. Ruessink, 2015: Infragravity-wave modulation of short-wave celerity in the surf zone. J. Geophys. Res. Oceans, 120, 6799-6814, https:// doi.org/10.1002/2015JC010708.
Tran, N., S. Labroue, S. Philipps, E. Bronner, and N. Picot, 2010: Overview and update of the sea state bias corrections for the Jason-2, Jason-1 and TOPEX missions. Mar. Geod., 33, 348-362, https://doi.org/10.1080/01490419.2010.487788.

Uunk, L., K. M. Wijnberg, and R. Morelissen, 2010: Automated mapping of the intertidal beach bathymetry from video images. Coastal Eng., 57, 461-469, https://doi.org/10.1016/ j.coastaleng.2009.12.002.

Valladeau, G., P. Thibaut, B. Picard, J. C. Poisson, N. Tran, N. Picot, and A. Guillot, 2015: Using SARAL/AltiKa to improve Ka-band altimeter measurements for coastal zones, hydrology and ice: The PEACHI prototype. Mar. Geod., 38, 124-142, https://doi.org/10.1080/01490419.2015.1020176.

Vousdoukas, M. I., L. Mentaschi, E. Voukouvalas, M. Verlaan, S. Jevrejeva, L. P. Jackson, and L. Feyen, 2018: Global probabilistic projections of extreme sea levels show intensification of coastal flood hazard. Nat. Commun., 9, 2360, https://doi.org/ 10.1038/s41467-018-04692-w.

Wright, L. D., and A. D. Short, 1984: Morphodynamic variability of surf zones and beaches: A synthesis. Mar. Geol., 56, 93-118, https://doi.org/10.1016/0025-3227(84)90008-2. 